\title{
Dauricine suppresses the growth of pancreatic cancer in vivo by modulating the Hedgehog signaling pathway
}

\author{
YING-BO ZHANG ${ }^{1}$, HONG-XIN FEI $^{2}$, JIA GUO $^{3}$, XIAO-JIE ZHANG ${ }^{1}$, SHU-LIANG WU $^{4}$ and LI-LI ZHONG ${ }^{5}$ \\ ${ }^{1}$ Ultramicropathology Experimental Center, Pathology College, Qiqihar Medical University, Qiqihar, Heilongjiang 161006; \\ ${ }^{2}$ Department of Basic Medicine, School of Nursing and Rehabilitation, Xinyu University, Xinyu, Jiangxi 338004; \\ ${ }^{3}$ Pathogenic Biology and Immunology Experimental Teaching Center, Qiqihar Medical University, Qiqihar, \\ Heilongjiang 161006; ${ }^{4}$ Department of Anatomy, Harbin Medical University, Harbin, Heilongjiang 150081; \\ ${ }^{5}$ Department of Pathology, The First Affiliated Hospital of Heilongjiang University of Chinese Medicine, \\ Harbin, Heilongjiang 150040, P.R. China
}

Received July 18, 2018; Accepted May 13, 2019

DOI: $10.3892 / \mathrm{ol} .2019 .10790$

\begin{abstract}
Pancreatic cancer is a highly malignant cancer associated with high expression levels of sonic hedgehog signaling molecule (Shh), patched 1 (Ptch1), smoothened frizzled class receptor (Smo) and glioma-associated oncogene family zinc finger 1 (Gli1) in the hedgehog (Hh) signaling pathway. Inhibition of the Hh signaling pathway is a potential therapeutic target for pancreatic cancer. The aim of the present study was to investigate the effects of dauricine in a pancreatic cancer BxPC-3 xenograft animal model and examine the underlying molecular mechanisms through Hh signaling pathway. High-and low-dose dauricine treatment significantly suppressed tumor growth with no concomitant effect on the spleen index. In addition, dauricine induced apoptosis and cell cycle arrest in pancreatic cancer BxPC-3 cells. The inhibitory effects of dauricine on pancreatic cancer may be mediated by the suppression of the Hh signaling pathway, as indicated by the decreases in the gene and protein expression levels of Shh, Ptch1, Smo and Gli1. The effects of dauricine were similar to those of 5-fluorouracil. Dauricine, a naturally occurring alkaloid, may be a potential anticancer agent for the treatment of pancreatic cancer.
\end{abstract}

\section{Introduction}

Pancreatic cancer is one of the deadliest malignant tumors in humans with $\sim 4 \%$ global mortality rate $(1,2)$. In the past decade, the rate of increase in the incidence of pancreatic

Correspondence to: Dr Hong-Xin Fei, Department of Basic Medicine, School of Nursing and Rehabilitation, Xinyu University, 2666 Sunshine Avenue, High-tech Zone, Xinyu, Jiangxi 338004, P.R. China

E-mail: 1ilin2169@163.com

Key words: dauricine, pancreatic cancer, hedgehog signaling pathway cancer in rural areas has exceeded that in the urban areas (3). The age standardized rate of pancreatic cancer in China (8.37 per 100,000$)$, and the associated mortality rate $(7.78$ per $100,000)$, is higher compared with that recorded in the United States (7.5 and 7.0, respectively), inducing the increased interests in pancreatic cancer treatment in China (3). The symptoms of pancreatic cancer are typically vague and non-specific in the early stages, which tends to delay the diagnosis $(4,5)$. Therefore, the majority of patients have metastatic cancer at the time of diagnosis (5). According to the American Cancer Society, the 1-and 5-year overall survival rates of patients with pancreatic cancer (all stages) are 20 and $7 \%$, respectively $(6,7)$. At present, very few effective therapies are available for pancreatic cancer. Surgery followed by the administration of compatible drugs is still considered the best therapeutic approach (8). However, the surgical mortality and postoperative recurrence rates remain high (8). Therefore, the development of new strategies for the treatment of pancreatic cancer is crucial.

The Hedgehog $(\mathrm{Hh})$ signaling pathway is a highly conserved pathway involved in the regulation of cell differentiation and organ development at the embryonic stage $(9,10)$. This pathway obtains its name from its ligand, a polypeptide intercellular molecule called Hedgehog, which has three homologues in mammals: Desert (Dhh), Indian (Ihh) and Sonic (Shh) (9). Among these, Shh is the most extensively studied homologue. Hh ligand interacts with membrane receptors patched 1 (Ptch1) and smoothened frizzled class receptor (Smo), and activates their downstream molecules and the nuclear transcription factor of the glioma-associated oncogene (Gli) family $(10,11)$. The expression of the molecules involved in the Hh signaling pathway is rarely detected in normal individuals; however, it is activated in malignant tumors (12), such as pancreatic (13), prostate (14), liver (15), ovarian (16), and breast (17) cancer. A global genomic analysis in 24 pancreatic cancers indicated twelve cellular signaling pathways that were genetically altered in 67 to $100 \%$ of patients, and genetic alterations in the Hedgehog signaling pathway were observed in all pancreatic cancers (18). High expression levels of Shh, Ptch1, Smo and GLI family zinc finger 1 (Gli1) in early-stage pancreatic cancer indicate an important role for the Hh signaling pathway in the 
development of pancreatic cancer (19). The abnormal activation of the Hh signaling pathway along with overexpression of Gli1 in pancreatic cancer (20) forms a positive feedback regulatory loop that induces the transcription of Ptch1, which further activates its target genes and results in uncontrolled activation of the Hh pathway. Gli target genes are involved in tumor cell growth, apoptosis, metastasis, neovascularization and epithelial-mesenchymal transition (21). Inhibition of the Hh signaling pathway reduces the growth, invasion and metastasis of pancreatic cancer cells (22), which suggests that it may be a potential therapeutic target in pancreatic cancer.

Dauricine is a bis-benzyltetrahydroisoquinoline alkaloid isolated from the Asian and Canadian moonseed (Menispermum dauricum and Menispermum canadense) (23). This natural compound exhibits various biological effects, including suppression of cancer cell growth and inhibition of transmembrane ion channels $(23,24)$. Dauricine has been demonstrated to prevent urothelial tumor cell proliferation (23) and to inhibit colon cancer growth by blocking the nuclear factor $\kappa \mathrm{B}$ $(\mathrm{NF}-\kappa \mathrm{B})$ pathway (24). Dauricine also attenuates inflammatory reactions (25), exerts neuroprotective effects $(26,27)$, and blocks potassium and calcium channels $(28,29)$. A previous study by our group examined the effects of a mixture of phenolic alkaloids containing daurisolin, dauricine, daurinoline and dauricicoline in pancreatic cancer BxPC-3 cells and BxPC-3 xenograft mice (30). The mixture exhibited a time-and dose-dependent inhibitory effect on the proliferation of the BxPC-3 cells, and induced $G_{0} / G_{1}$ phase arrest and cell apoptosis; it also inhibited tumor growth in the BxPC-3 xenograft in vivo. However, the therapeutic effects of dauricine in the context of pancreatic cancer have not been investigated, although the antitumor function of dauricine has been demonstrated in colon (24), renal (31) and urothelial cancer cells (23). The present study was designed to investigate the effects of dauricine on BxPC-3 transplanted pancreatic cancer in nude mice. Additionally, the underlying molecular mechanisms of the inhibitory effect of dauricine on pancreatic cancer growth were investigated.

\section{Materials and methods}

Drugs, reagents and kits. Dauricine (cat. no. MUST-1702 2102) (Fig. 1) was purchased from Guangzhou Poetry Man Dan Biotechnology Co., Ltd.. RNase A, TRIzol ${ }^{\circledR}$ and antibodies against Shh (cat. no. 2207) and Glil (cat. no. 3538) were purchased from Invitrogen; Thermo Fisher Scientific, Inc. Antibodies against Ptch1 (cat. no. ab39266) and Smo (cat. no. ab72130) were purchased from Abcam. 5-Fluorouracil (5-FU), propidium iodide (PI), sodium dodecyl sulfate (SDS; cat. no. L5750) and Tween-20 (cat. no. P1379) were purchased from Sigma-Aldrich; Merck KGaA. Anti-GAPDH antibody (cat. no. CW0100A) and a high sensitivity chemiluminescence detection kit (cat. no. CW0049A) were purchased from Kangwei Century Biotechnology Co. Ltd. (http://www. cwbiotech.com/). Protein extraction reagent (cat. no. P0028-1) was purchased from Beyotime Institute of Biotechnology. PrimeScript Reverse Transcription (RT) Reagent kit and SYBR Premix Ex Taq were obtained from Takara Bio, Inc..

Pancreatic cancer animal model. The human pancreatic cancer BxPC-3 cell line was obtained from the Cell Bank/Stem
Cell Bank, Shanghai Institute of Life Sciences, Chinese Academy of Sciences. The cells were cultured in RPMI 1640 complete medium (HyClone; GE Healthcare Life Sciences) and incubated at $37^{\circ} \mathrm{C}$ in $5 \% \mathrm{CO}_{2}$. The cells were digested with $0.25 \%$ trypsin-EDTA, collected and adjusted to a concentration of $5 \times 10^{6}$ cells $/ \mathrm{ml}$ of medium.

A total of $50 \mathrm{BALB} / \mathrm{c}$ nude mice (age, 4-6 weeks; 25 male and 25 female; weight, $18 \pm 2 \mathrm{~g}$ ) were obtained from the Shanghai SLAC Laboratory Animal Co. Ltd. Mice were housed at $23^{\circ} \mathrm{C}$ and $55 \%$ humidity with 12 light/12 dark cycle at the Comparative Medicine Facility, Heilongjiang University of Chinese Medicine (Harbin, China) and provided with ad libitum access to water and food. The experimental protocols were approved by the Animal Care and Use Committee of the Heilongjiang University of Chinese Medicine.

The pancreatic cancer BxPC-3 xenograft animal model was established according to previously described methods (30). Cell suspension $\left(0.2 \mathrm{ml} ; 5 \times 10^{6}\right.$ cells $\left./ \mathrm{ml}\right)$ was inoculated subcutaneously into the right armpit of the nude mice. Flattened or round lumps were observed on days 7 to 10 post-injection, which indicated successful inoculation. The tumor size was monitored by visual observation daily. Only one tumor was observed in each animal; no animals exhibited multiple subcutaneous tumors. Specific criteria for humane endpoints included: i) A tumor size that $>1.5 \mathrm{~cm}$; ii) tumors becoming ulcerated, infected or necrotic with breaks in the overlying skin; and iii) body weight loss of $>20 \%$. Other general signs of illness, such as inactivity, hunched posture or ruffled appearance, were also included. The use of humane endpoints was monitored and reviewed throughout the experiment. None of the animals exhibited the signs of these endpoints until the end of the experiment.

Experimental design. A total of 40 pancreatic cancer BxPC-3 xenograft-bearing animals were randomly divided into four groups (n=10 mice/group) as follows: i) The saline group; ii) the 5-FU group; iii) the low-dose dauricine group; and iv) the high-dose dauricine group. Healthy BALB/c nude mice without BxPC-3 xenografts were used as the control group $(n=10)$. Mice in the saline group received intraperitoneal injections of saline, whereas mice in the low-and high-dose dauricine groups received intraperitoneal injections of dauricine at 6 and $12 \mathrm{mg} / \mathrm{kg}$ body weight, respectively. Mice in the 5 -FU group were inoculated with 5-FU (20 mg/kg). 5-FU was selected as the positive control for the evaluation of the effects of dauricine. Control mice received injections of an equal volume of saline. The treatments were administered at 10 a.m. daily for 21 days. Following the completion of treatment, the animals were weighed and euthanized the next day by cervical dislocation for sample collection. Death was verified by the absence of a heart beat and the onset of rigor mortis.

Tumor inhibition rate and spleen index. The tumor and spleen of each mouse were dissected, washed with sterile saline and dried using filter paper. The tumor volume was calculated using the following formula: Volume $=(4 \pi / 3) \times(L / 2)^{3}$, where $\mathrm{L}$ is the mean tumor length measured in 3 dimensions. It was observed that maximum tumor diameter was $\sim 1.2 \mathrm{~cm}$, and the tumor volume in the saline control group reached $\sim 1,000 \mathrm{~mm}^{3}$ at 21 days, which was in accordance with the results from 


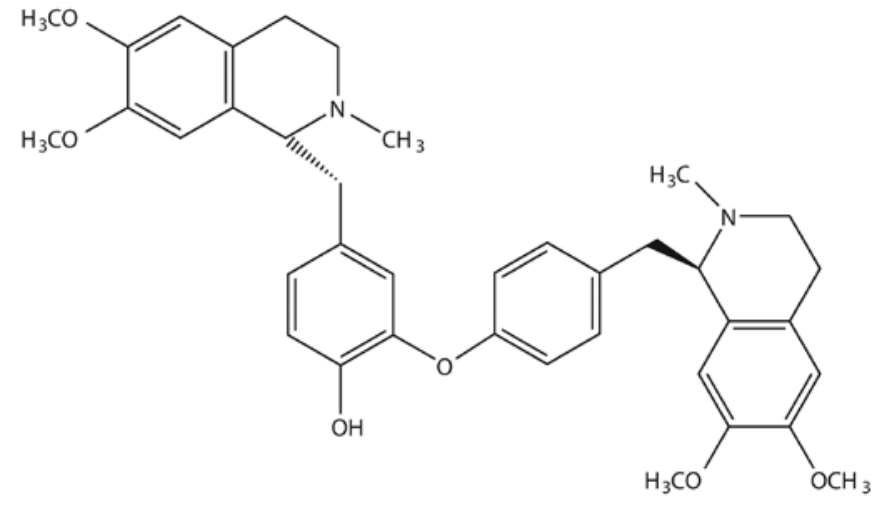

Figure 1. Chemical structure of dauricine, a bis-benzyltetrahydroisoquinoline alkaloid.

our previous study (30). The weights of the tumor and spleen were measured. The spleen index was calculated as spleen weight $(\mathrm{g}) \times 1,000 /$ body weight $(\mathrm{g})$.

Transmission electron microscopy (TEM). Fresh tumor tissues from each group were cut into $\sim 1 \mathrm{~mm}^{3}$ cubes, immersed in $2.5 \%$ glutaraldehyde for $2 \mathrm{~h}$, washed 3 times with $1 \mathrm{X}$ PBS, and fixed in $1 \%$ citric acid for $1.5 \mathrm{~h}$. Following washing 3 times, dehydration was performed by a graded ethanol series with 50, 70 and $90 \%$ ethanol, $90 \%$ ethanol and $90 \%$ acetone (1:1), and $90 \%$ acetone at $4{ }^{\circ} \mathrm{C}$ followed by $100 \%$ acetone at room temperature. The duration of each step was 15-20 min. The samples were soaked in propylene oxide and epoxy resin Epon 812 mixture $(1: 1)$, and embedded at $37^{\circ} \mathrm{C}$ in epoxy resin Epon 812 . The cubes were sliced $(4 \mu \mathrm{m})$ and stained with $2 \%$ toluidine blue at room temperature for $3 \mathrm{~min}$. Ultra-thin sections were placed in 200- $\mu$ m copper mesh, stained with uranyl acetate and lead citrate at room temperature for $3 \mathrm{~min}$, and examined at x10,000 magnification, under a transmission electron microscope HT7700 (Hitachi High-Technologies Corporation) equipped with Hitachi's EMIP-SP database software (Hitachi High-Technologies Corporation).

Apoptotic assay. The surface fiber membrane of tumor tissues was removed and tissues were placed on ice, smashed and ground to obtain a single cell suspension. The late apoptotic rate of tumor cells was evaluated using Annexin V-FITC Apoptosis Detection Kit I (BD Biosciences) according to the manufacturer's protocol. Cells were incubated with $5 \mu \mathrm{l} / \mathrm{ml}$ Annexin V-FITC for $30 \mathrm{~min}$ in the dark and florescence was measured using a BD FACSCanto ${ }^{\mathrm{TM}}$ II flow cytometer (BD Biosciences).

Cell cycle analysis. Single cell suspension was obtained as described above. Cell concentration was adjusted to $2 \times 10^{6} / \mathrm{ml}$. Cells from different groups were seeded in a 6-well plate and treated with saline, 5-FU, low-dose dauricine or high-dose dauricine at $37^{\circ} \mathrm{C}$ for $24 \mathrm{~h}$. Cells were fixed with $70 \%$ ethanol overnight at $-20^{\circ} \mathrm{C}$, washed and resuspended. A total of $1 \mathrm{ml}$ of the cell suspension was incubated with $1.6 \mathrm{ml}$ RNase A $(1 \mathrm{mg} / \mathrm{ml})$ at $37^{\circ} \mathrm{C}$ for $30 \mathrm{~min}$ and centrifuged at $12,000 \mathrm{x} \mathrm{g}$ for $5 \mathrm{~min}$. The cell pellet was suspended in $0.4 \mathrm{ml} \mathrm{PBS}$, mixed with PI at $100 \mu \mathrm{g} / \mathrm{ml}$ for $10 \mathrm{~min}$ at room temperature and subjected to cell cycle analysis by flow cytometry using a BD FACSCanto ${ }^{\mathrm{TM}}$ II flow cytometer (BD Biosciences).

Immunohistochemical analysis. Tumor tissues were harvested, fixed in $10 \%$ formalin for $4 \mathrm{~h}$ at room temperature, dehydrated by a graded ethanol series, and placed in xylene for $30 \mathrm{~min}$ at room temperature. Tissues were embedded in paraffin, sectioned into $4-\mu \mathrm{m}$ thick slices using a microtome and mounted on Poly-L-lysine slides. Following deparaffination by immersing the slides in xylene for 3 min twice, 1:1 xylene, $100 \%$ ethanol for $3 \mathrm{~min}$, and a graded descending ethanol series (100-50\%), slides were washed by running tap water and incubated with $3 \% \mathrm{H}_{2} \mathrm{O}_{2}$ for $10 \mathrm{~min}$ at room temperature, rinsed with distilled water and heated in a microwave oven for $5 \mathrm{~min}$ for antigen retrieval. Slides were blocked with $0.5 \% \mathrm{BSA}$ at room temperature for $20 \mathrm{~min}$, incubated with respective primary antibodies $\left(1: 1,000\right.$ dilution) for $2 \mathrm{~h}$ at $37^{\circ} \mathrm{C}$ and rinsed with PBS for $5 \mathrm{~min}$, followed by the addition of the secondary antibody (1:10,000 dilution) at $37^{\circ} \mathrm{C}$ for $30 \mathrm{~min}$. Following rinsing with PBS for $3 \mathrm{~min}$, the slides were incubated with 3,3'-diaminobenzidine for $10 \mathrm{~min}$ at room temperature, washed with water and counterstained with hematoxylin for $5 \mathrm{~min}$. The slides were covered, sealed and examined under a light microscope (Olympus Corporation). Seven fields of view (x100 magnification) were randomly selected and photographed. The integrated optical density (OD) of positive cells was analyzed and compared using the Motic Med 6.0 digital medical image analysis system (Motic Instruments Inc.).

Western blot analysis. Tumor tissues were homogenized in protein extraction reagent (cat. no. P0028-1; Beyotime Institute of Biotechnology) and centrifuged at $15,000 \mathrm{x}$ g for $10 \mathrm{~min}$ at $4^{\circ} \mathrm{C}$. Total protein was quantified using a bicinchoninic acid assay, denatured at $100^{\circ} \mathrm{C}$ for $5 \mathrm{~min}$, and stored at $-80^{\circ} \mathrm{C}$. Protein samples $(20 \mu \mathrm{g})$ were separated by electrophoresis for $1 \mathrm{~h}$ at $75 \mathrm{~V}$ on a $10 \%$ SDS-PAGE gel. The proteins were transferred onto a PVDF membrane, blocked with 5\% BSA overnight at $4^{\circ} \mathrm{C}$, and incubated with primary antibodies against GAPDH (1:3,000), Shh (1:800), Ptch (1:1,000), Smo (1:2,000) and Gli1 $(1: 2,000)$ at $37^{\circ} \mathrm{C}$ for $2 \mathrm{~h}$. The membrane was washed, incubated with horseradish peroxidase-conjugated secondary antibodies at $37^{\circ} \mathrm{C}$ for $1 \mathrm{~h}$, and examined using a chemiluminescence detection kit. The images were captured and analyzed with an HMIAS-2000 High-Definition Color Medical Analysis system (Wuhan Qianping Imaging Technology Co., Ltd.). GAPDH was used as an internal control. The results are expressed as the ratio of density of individual target proteins to the expression of respective GAPDH.

$R T$-quantitative polymerase chain reaction $(R T-q P C R)$. mRNA from tumor tissues was extracted using TRIzol according to the manufacturer's protocol. A total of $500 \mathrm{ng}$ RNA was mixed in a $10 \mu \mathrm{l}$ reaction containing $2 \mu \mathrm{l} 5 \mathrm{X}$ PrimeScript Buffer, $0.5 \mu \mathrm{l}$ PrimeScript RT Enzyme Mix, $0.5 \mu \mathrm{l}$ Oligo dT Primer $(50 \mu \mathrm{M})$, and $0.5 \mu \mathrm{l}$ Random 6 mers $(100 \mu \mathrm{M})$. The reaction mixture was incubated under the following condition: $37^{\circ} \mathrm{C}$ for $15 \mathrm{~min}$, and $85^{\circ} \mathrm{C}$ for $5 \mathrm{sec}$. SYBR Premix Ex Taq was used for PCR reaction. The qPCR system was prepared according to the manufacturer's instructions. Primers were designed and synthesized by Shanghai Shenggong Biology Engineering 
Technology Service, Ltd. The primer sequences were as follows: Shh forward, 5'-GCTCGGTGAAAGCAGAGAACT-3' and reverse 5'-CCAGGAAAGTGAGGAAGTCG-3'; Smo forward, 5'-CTGGTGTGGTTTGGTTTGTG-3' and reverse, 5'-CAG GTGGAAGTAGGAGGTCTTG-3'; Ptch1 forward, 5'-CTC CTTTGCGGTGGACAA-3' and reverse, 5'-CCTCAGCCT TATTCAGCATTTC-3'; Gli1 forward, 5'-ATCCTTACCTCC CAACCTCTGT-3' and reverse, 5'-CCAACTTCTGGCTCT TCCTGTA-3'; and GAPDH forward, 5'-AGAAGGCTGGGG CTCATTTG-3' and reverse, 5'-AGGGGCCATCCACAGTCT TC-3'. GAPDH was used as an internal control. The qPCR thermocycling conditions were as follows: Initial denaturation at $95^{\circ} \mathrm{C}$ for $10 \mathrm{sec}$, followed by 40 cycles of $95^{\circ} \mathrm{C}$ for $5 \mathrm{sec}$ and $60^{\circ} \mathrm{C}$ for $34 \mathrm{sec}$ for amplification. The reaction was performed using an Applied Biosystems 7300 Real-Time PCR System (Thermo Fisher Scientific, Inc.). The data were processed using the $2^{-\Delta \Delta \mathrm{Cq}}$ method (32) and gene expression was expressed as a fold-change relative to the saline group.

Statistical analysis. The statistical software SPSS v21.0 (IBM Corp.) was used for data analysis. Normally distributed data are expressed as the mean \pm standard deviation. One-way analysis of variance followed by Tukey's post hoc test was used for multiple group comparisons. $\mathrm{P}<0.05$ was considered to indicate a statistically significant difference.

\section{Results}

Dauricine inhibits the proliferation of BxPC-3 pancreatic cancer xenografts in mice. Following the injection of BxPC-3 cells, the mice developed pancreatic cancer xenografts (mean tumor weight in saline-treated mice, $0.4052 \pm 0.0309 \mathrm{~g}$ ) (Fig. 2A). Treatment with 5-FU, low-dose dauricine or high-dose dauricine significantly inhibited the tumor growth $(0.2739 \pm 0.0249,0.2801 \pm 0.0262$ and $0.2058 \pm 0.0161 \mathrm{~g}$, respectively; $\mathrm{P}<0.05)$ compared with the control saline group. High-dose dauricine exhibited the most potent antitumor effect, as indicated by the lowest tumor weight (Fig. 2A). Mice in the control group did not develop xenografts of pancreatic cancer.

Effects of dauricine on the spleen index of mice with pancreatic cancer BXPC-3 xenografts. No significant difference in the spleen index was observed between mice in the control and saline groups. However, treatment with 5-FU significantly decreased the spleen index as compared with the saline group $(\mathrm{P}<0.05)$ (Fig. 2B), which suggested that 5-FU may have an effect on spleen function. No significant differences were observed between the control and the low-or high-dose dauricine treatment groups (Fig. 2B), which indicated that dauricine had no influence on spleen weight and function.

TEM. TEM examination demonstrated that tumor cells in the saline group were elliptical with a large nucleus, high heterogeneity and a clear double-layered nuclear membrane (Fig. 3A). A high quantity of organelles and abundant free ribosomes was observed in the cytoplasm. Mitochondrial cristae were clearly visible. In the high-dose dauricine group, the tumor cells were small in size and exhibited nuclear condensation; chromatin clumps were distributed below the nuclear membrane. Heterochromatin was clustered on one side of the nucleus in a half-moon shape. The nuclear membrane was clear and the plasma membrane was intact. Parts of the cytoplasm and nucleoplasm were detached from the cell body, forming apoptotic bodies, accompanied by tumor cell necrosis and granulocyte infiltration. A decrease in the number of free ribosomes was also observed. Mitochondrial cristae were dissolved and there was an increase in the number of apoptotic cells (Fig. 3A). In the low-dose dauricine group, tumor cells were irregular in shape with a clear cell membrane and an intact nuclear membrane. Nuclear material was condensed and heterochromatin was clustered on one side of the nucleus. Mitochondrial vacuoles were degenerated and free ribosomes were abundant, which was consistent with the early apoptotic state (Fig. 3A). In the 5-FU group, tumor cells exhibited a regular shape with a clear nuclear membrane and obvious nucleoli. Free ribosomes were abundant and the rough endoplasmic reticulum was slightly expanded. Mitochondrial vacuoles were generated, and some tumor cells exhibited early apoptosis and lymphocytic infiltration (Fig. 3A).

Effects of dauricine on apoptosis and the cell cycle of pancreatic cancer BxPC-3 xenografts. The apoptotic cell percentages in the saline, high-low-dose dauricine, and 5-FU groups were $5.0017 \pm 1.2329,8.1800 \pm 1.1675,8.0717 \pm 1.5027$ and $7.6933 \pm 1.3402 \%$, respectively (Fig. 3B and C). The percentages of apoptotic cells in the high-and low-dose dauricine, and 5-FU groups were significantly increased compared with that in the control group $(\mathrm{P}<0.05$; Fig. $3 \mathrm{~B}$ and $\mathrm{C})$. No significant differences were observed between the high-dose dauricine, low-dose dauricine and 5-FU groups.

In the high- and low-dose dauricine, and 5-FU groups, the number of cells in the $G_{1}$ phase was significantly higher, whereas the number of cells in the G2 phase was significantly lower compared with that in the saline group (all $\mathrm{P}<0.05$; Fig. 4). These results indicated cell cycle arrest in the $G_{1}$ phase following drug treatment. The number of cells in the $\mathrm{S}$ phase in the high-dose dauricine and 5-FU groups was significantly lower compared with that in the saline group; however, no significant difference was observed between the low-dose dauricine group and the saline group (Fig. 4).

Effects of dauricine on $\mathrm{Hh}$ pathway molecule protein expression levels in pancreatic cancer BxPC-3 xenografts. Immunohistochemistry results demonstrated that the protein expression levels of Shh, Smo, Ptch1 and Gli1 in the high-dose dauricine and 5-FU groups were significantly lower compared with those in the saline group (Fig. 5). This indicated that dauricine may inhibit the Hh signaling pathway and suppress the growth of cancer cells. This result was validated by western blotting, which revealed significantly lower protein expression levels of Shh, Smo, Ptch1 and Gli1 in the high-dose dauricine and 5-FU groups (Fig. 6).

Western blotting results also demonstrated that Shh, Smo, Ptch1 and Gli1 protein expression levels in the low-dose dauricine group were significantly lower compared with those in the saline group (Fig. 6); however, this difference was not observed in the immunohistochemistry assay (Fig. 5). 

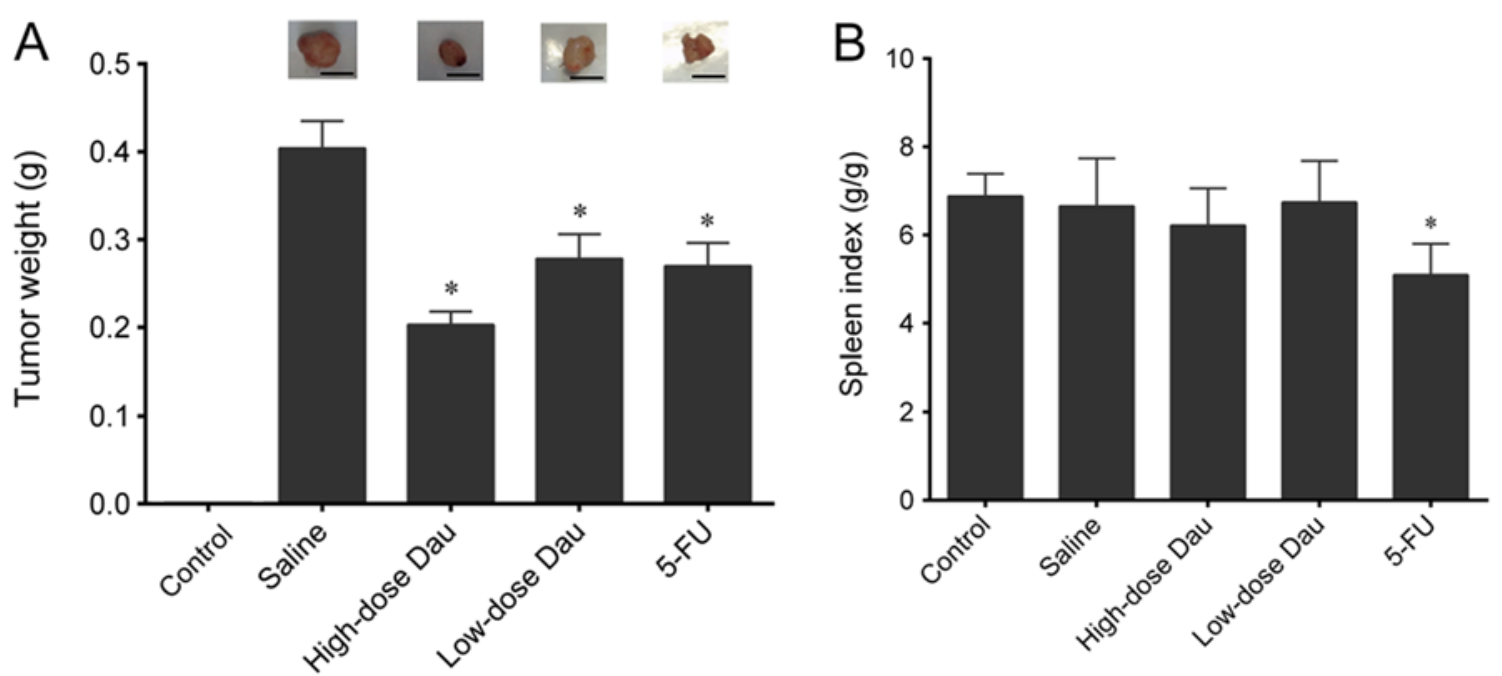

Figure 2. Effects of dauricine on tumor weight and spleen index of mice with pancreatic cancer BxPC-3 xenografts. (A and B) A pancreatic cancer BxPC-3 xenograft animal model was established by subcutaneous injection of BxPC-3 cells into the right armpit of nude mice. Mice in the saline group received intraperitoneal injections of saline; mice in the low-and high-dose dauricine groups received intraperitoneal injections of 6 and $12 \mathrm{mg} / \mathrm{kg}$ dauricine, respectively; the 5-FU group received $20 \mathrm{mg} / \mathrm{kg}$ 5-FU; control mice were not injected with BxPC-3 cells and received an equal volume of saline. (A) Tumor and (B) spleen tissues were collected and weighed, and the spleen index was calculated. Scale bar, $1 \mathrm{~cm}$. " $\mathrm{P}<0.05$ vs. saline. Dau, dauricine; 5-FU, 5-fluorouracil.

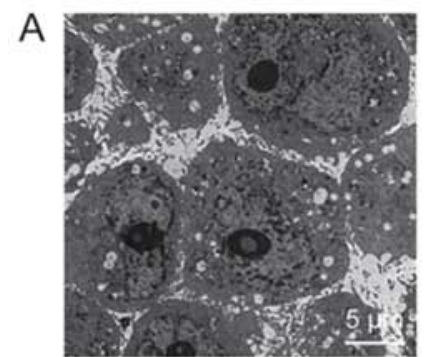

Saline

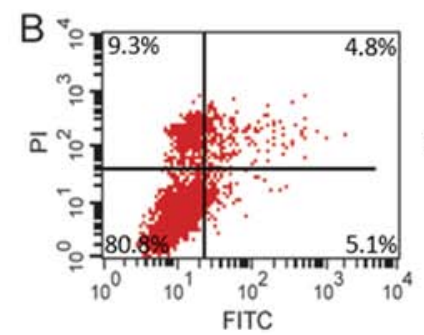

Saline

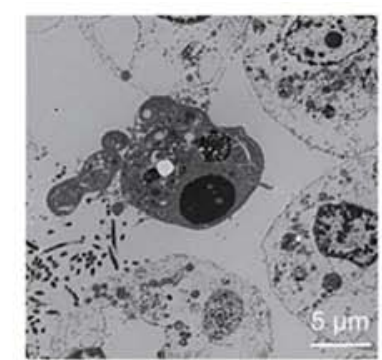

High-dose Dau

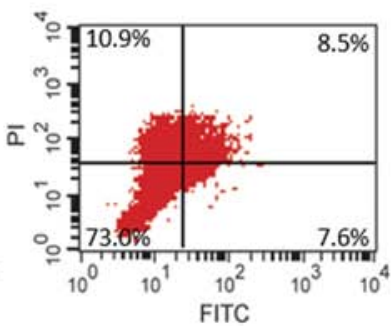

High-dose Dau

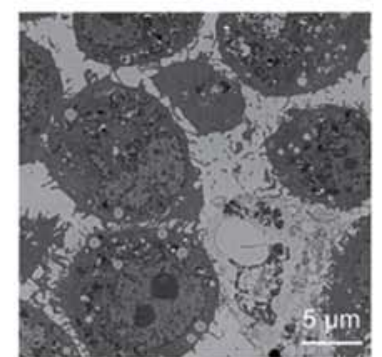

Low-dose Dau

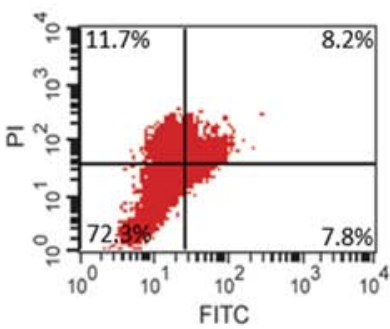

Low-dose Dau

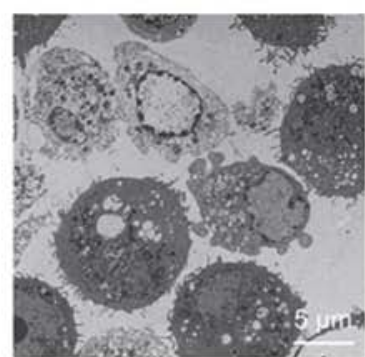

5-FU

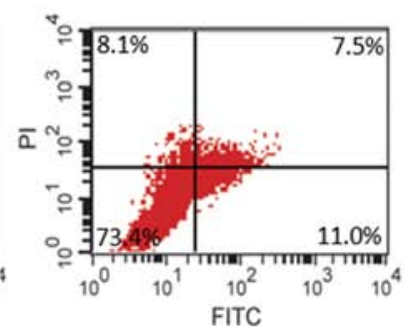

5-FU

C

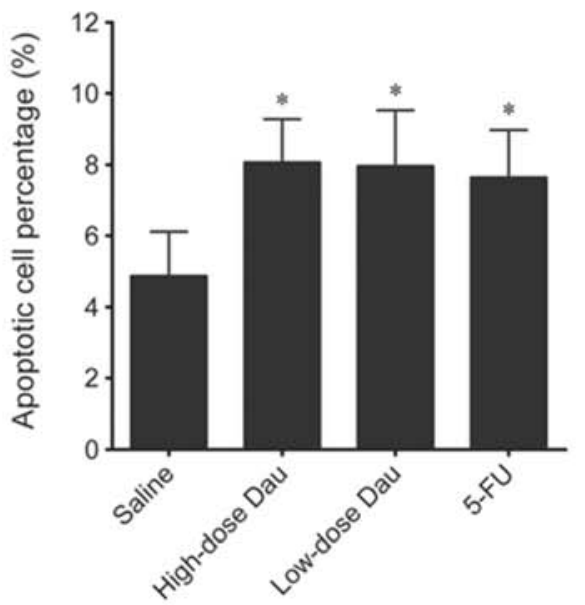

Figure 3. Tumor morphology and apoptosis analysis in pancreatic cancer BxPC-3 xenografts of mice treated with dauricine. (A) Morphological examination by transmission electron microscopy. (B) Analysis of apoptosis by flow cytometry. (C) The percentage of apoptotic cells following different treatments. * $\mathrm{P}<0.05$ vs. saline. Dau, dauricine; 5-FU, 5-fluorouracil; PI, propidium iodide. 

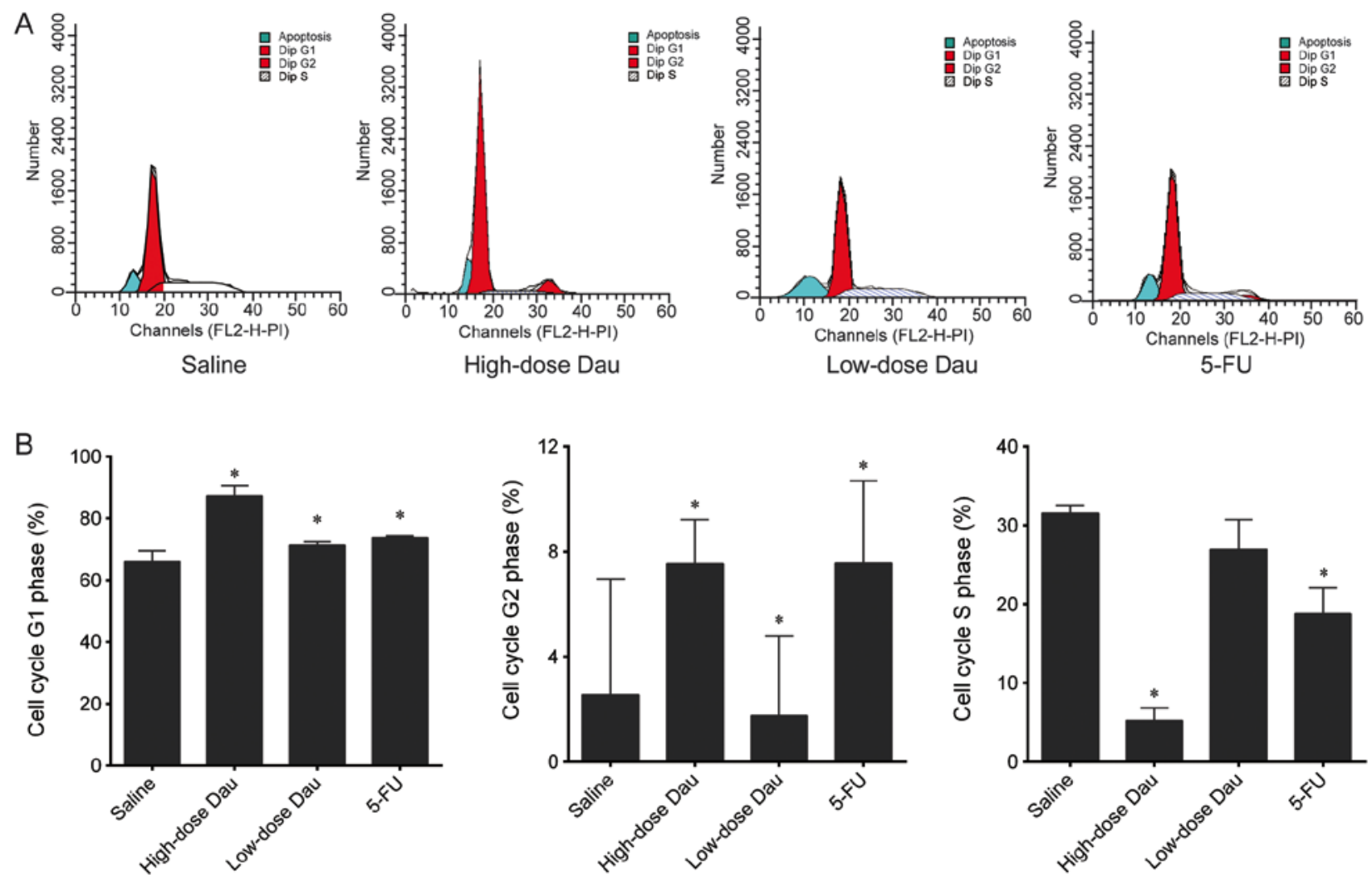

Figure 4. Cell cycle analysis of pancreatic cancer BxPC-3 xenografts of mice treated with dauricine. (A) Representative histograms of flow cytometry. (B) Cell percentages in different cell phases. ${ }^{*} \mathrm{P}<0.05$ vs. saline. Dau, dauricine; 5 -FU, 5 -fluorouracil.

Effects of dauricine on the expression of genes in the $H$ h pathway in pancreatic cancer BxPC-3 xenografts. The mRNA expression levels of Shh, Smo, Ptch1 and Gli1 were further tested in BxPC-3 pancreatic cancer xenografts following different treatments. The high-dose dauricine and 5-FU groups exhibited a significant decrease in the expression levels of these genes compared with the saline group (Fig. 7). However, in the low-dose dauricine group, the mRNA expression levels of Shh, Ptch1, Smo and Gli1 were not significantly different compared with those of the saline group (Fig. 7).

\section{Discussion}

Pancreatic cancer is an aggressive and highly lethal malignancy with limited effective treatment options. In the present study, the effect of dauricine on BxPC-3 pancreatic cancer xenografts and the role of Hh signaling pathway as an underlying molecular mechanism were investigated.

Dauricine, a bioactive component extracted from the moonseed rhizome, has demonstrated promising pharmacological attributes in clinical settings $(24,30)$. It has long been used as a traditional Chinese medicine remedy for inflammatory disorders. Several studies have investigated the inhibitory effect of dauricine on tumor growth. In a study by Zhang et al (31), dauricine effectively inhibited the viability of four renal cell carcinoma cell lines through the induction of cell cycle arrest at the $\mathrm{G}_{0} / \mathrm{G}_{1}$ phase and the promotion of apoptosis. Dauricine has been demonstrated to exhibit an inhibitory effect on urinary tract tumor cells at minimum drug concentrations of 3.81-5.15 $\mu \mathrm{g} / \mathrm{ml}$ (23). In a previous study, dauricine suppressed cell proliferation and invasion, and induced the apoptosis of colon cancer cells by inhibiting the NF- $\kappa \mathrm{B}$ pathway and its downstream gene expression (24). Dauricine has been demonstrated to inhibit angiogenesis in human breast cancer by blocking vascular endothelial growth factor expression and inducing accumulation of hypoxia-inducible factor 1 subunit $\alpha$ protein (33). These findings suggest that dauricine may be a potential therapeutic agent for the treatment of cancer. However, the antitumor effects of dauricine in the context of pancreatic cancer have not been reported. A previous study on colon cancer in mice used $40 \mathrm{mg} / \mathrm{kg}$ dauricine injected every 2 days until day 9 (24), which showed that dauricine significantly suppressed colonic tumor growth. Our previous study demonstrated the significant in vivo effects of a 21-day treatment with 10 and $20 \mathrm{mg} / \mathrm{kg}$ phenolic alkaloid mixture on pancreatic cancer (30). Therefore, a 21-day treatment with two doses of dauricine ( 6 and $12 \mathrm{mg} / \mathrm{kg}$ body weight) was tested in the present study. H\&E staining was conducted in our previous study (30), which demonstrated that the model was well established; therefore, it was not performed in the present study. The absence of H\&E staining is a limitation of the present study, as the morphological changes of pancreatic cancer tissues in the animal models were not demonstrated. However, $12 \mathrm{mg} / \mathrm{kg}$ dauricine treatment exhibited stronger effects in decreasing the tumor size compared with $6 \mathrm{mg} / \mathrm{kg}$, although $6 \mathrm{mg} / \mathrm{kg}$ dauricine also had a minor inhibitory effect. The effects of dauricine were comparable to those of 5-FU. $5-\mathrm{FU}$ is a chemotherapeutic agent widely used for the treatment of a number of cancer types, including breast (34), skin (35), stomach (36), gullet (37), bowel (38) and pancreatic 

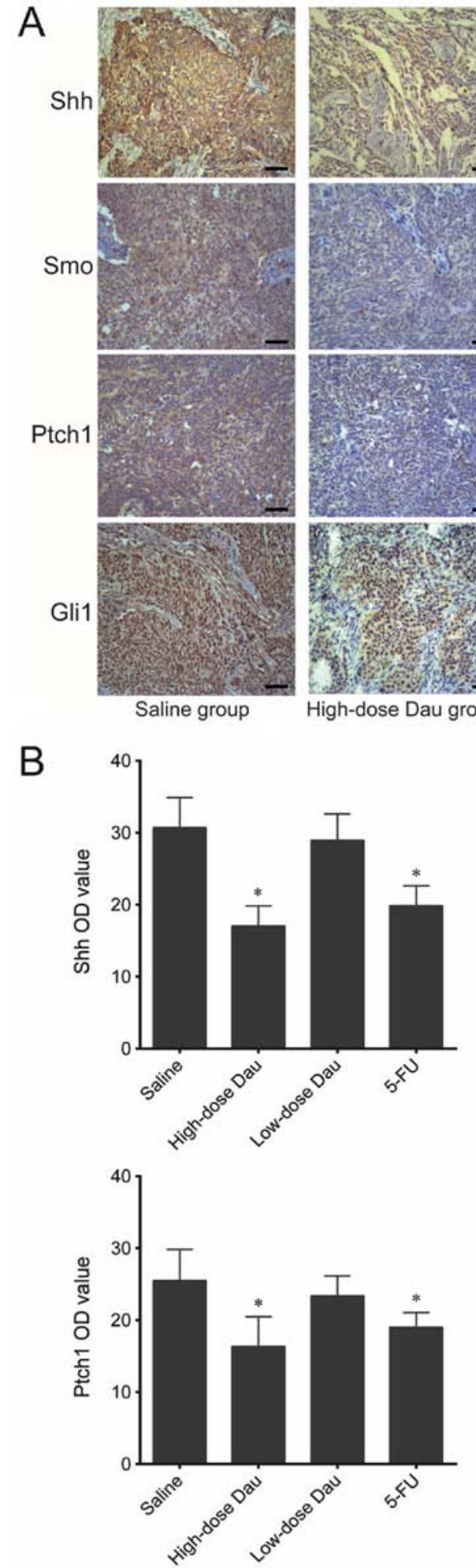
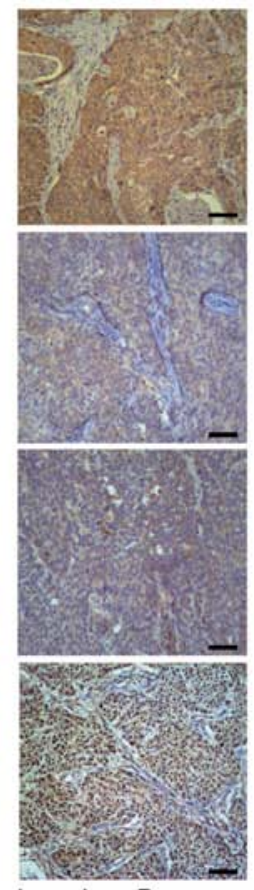

Low-dose Dau group
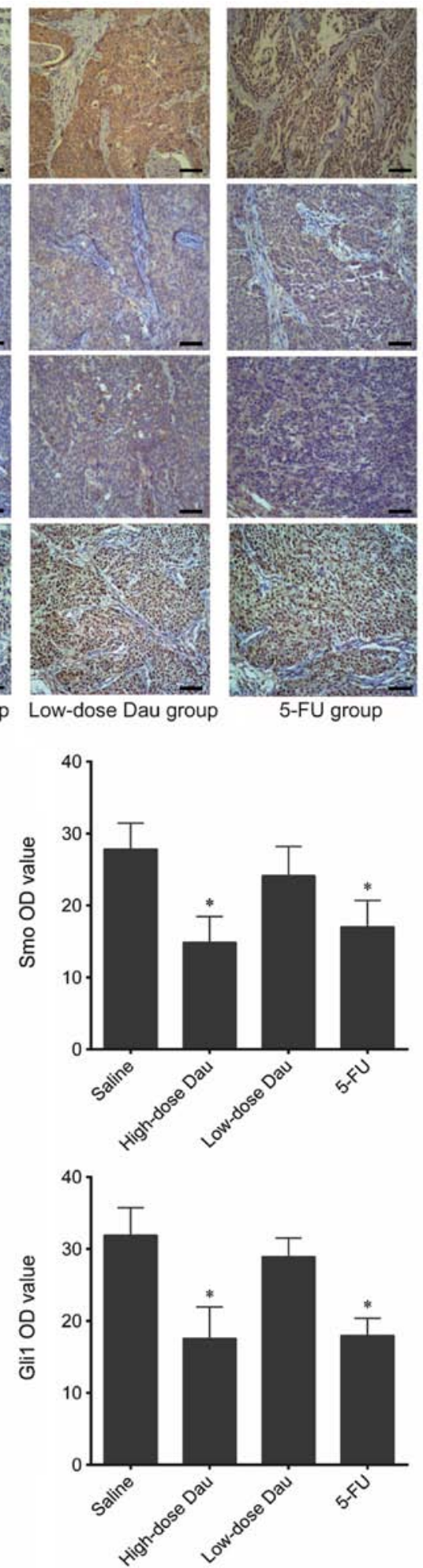

Figure 5. Immunohistochemistry analysis of Shh, Smo, Ptch1 and Gli1 in BxPC-3 pancreatic cancer xenografts. (A) Representative images of immunohistochemistry (x100 magnification). Scale bar, $200 \mu \mathrm{m}$. (B) OD analysis of the immunohistochemistry results. " $\mathrm{P}<0.05$ vs. saline. Dau, dauricine; 5-FU, 5-fluorouracil; Gli1, glioma-associated oncogene family zinc finger 1; OD, optical density; Ptch1, patched 1; Shh, sonic hedgehog signaling molecule; Smo, smoothened, frizzled class receptor.

cancer (39). 5-FU works as an antimetabolite and prevents cell proliferation through inhibition of thymidylate synthase, which in turn prevents nucleotide synthesis and arrests cell division (40). However, it is associated with several side effects, including mouth sores, anorexia, nausea, vomiting, diarrhea, photophobia, leukocytopenia, erythrocytopenia and thrombocytopenia (41). These side effects increase the risk of infection, bleeding and anemia (42). In the present study, 5-FU was selected as the positive control for the evaluation of the effects of dauricine. Animals treated with 5-FU exhibited abnormal spleen function, as reflected in the significantly decreased spleen index compared with that of the saline and 

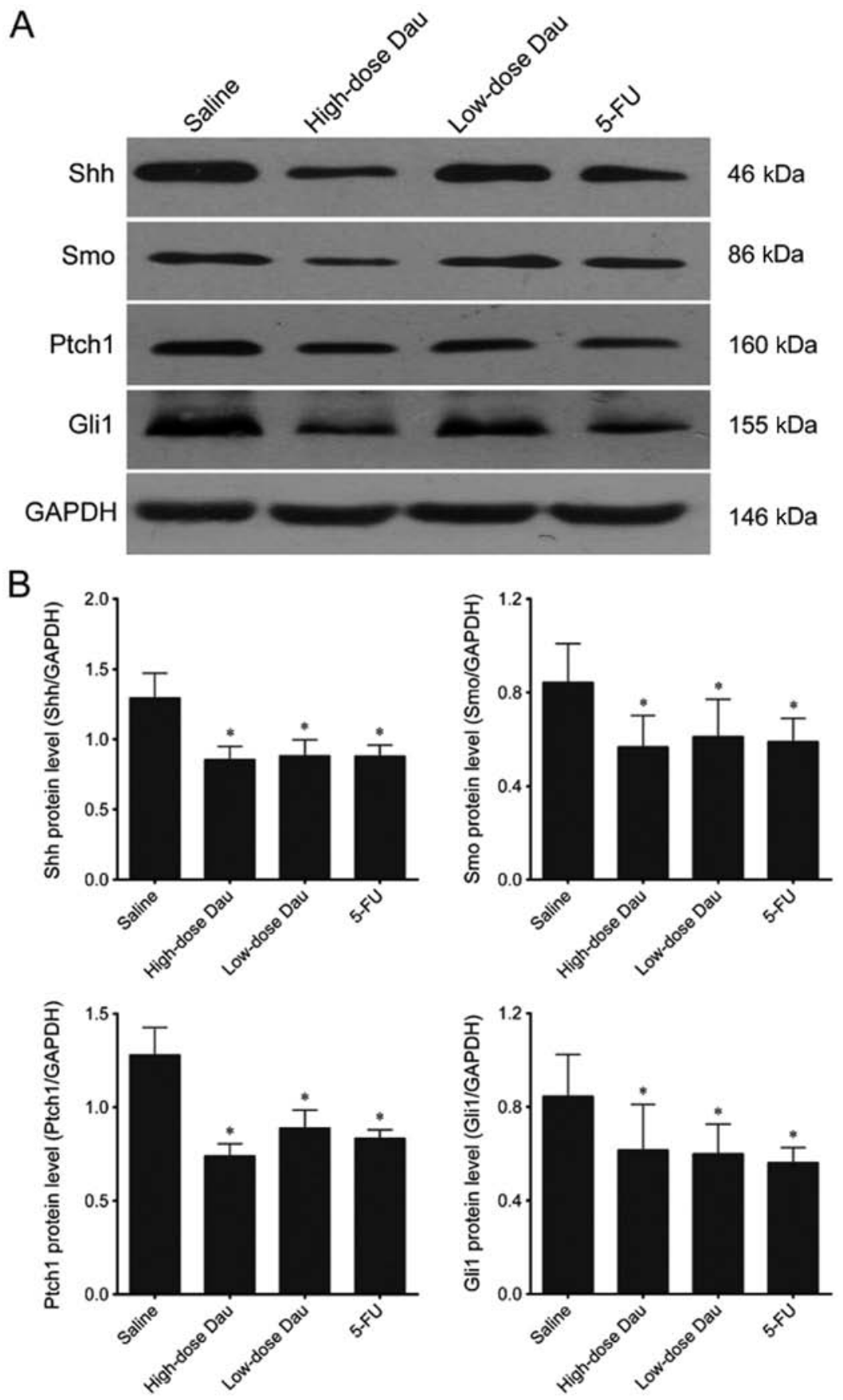

Figure 6. Effects of dauricine on Shh, Smo, Ptch1 and Gli1 protein expression levels in pancreatic cancer BxPC-3 xenografts. (A) Representative western blotting. (B) Densitometric analysis of the western blotting data. The results were calculated and expressed as a ratio of density of individual target proteins to the expression of GAPDH. "P<0.05 vs. saline. Dau, dauricine; 5-FU, 5-fluorouracil; Gli1, glioma-associated oncogene family zinc finger 1; Ptch1, patched 1; Shh, sonic hedgehog signaling molecule; Smo, smoothened, frizzled class receptor.

control groups. The spleen index results demonstrated that the subcutaneous injection of BxPC-3 pancreatic cancer cells and the subsequent growth of cancer did not affect the spleen weight when compared with the control mice. Animals in the high-and low-dose dauricine groups also exhibited no significant differences in spleen index compared with the saline and control groups. Thus, dauricine may be a safer agent with fewer side effects compared with 5-FU. The metabolic effects and pulmonary toxicity of dauricine have been investigated in CD-1 mice in a previous study; mice that received intraperitoneal injections of dauricine at 50,100 or $150 \mathrm{mg} / \mathrm{kg}$ did not exhibit any changes in blood urea nitrogen, serum aspartate aminotransferase or serum alanine aminotransferase, whereas a dose-dependent increase in lactate dehydrogenase activity was observed in lung lavage fluids (43). The results of the present study demonstrated that intraperitoneal injection of dauricine at 6 and $12 \mathrm{mg} / \mathrm{kg}$ significantly inhibited tumor growth in nude mice with no concomitant changes in the spleen index. However, the molecular mechanisms that mediate this effect are not understood.

A potential mechanism of the effects of dauricine in pancreatic cancer is through promotion of apoptosis and 

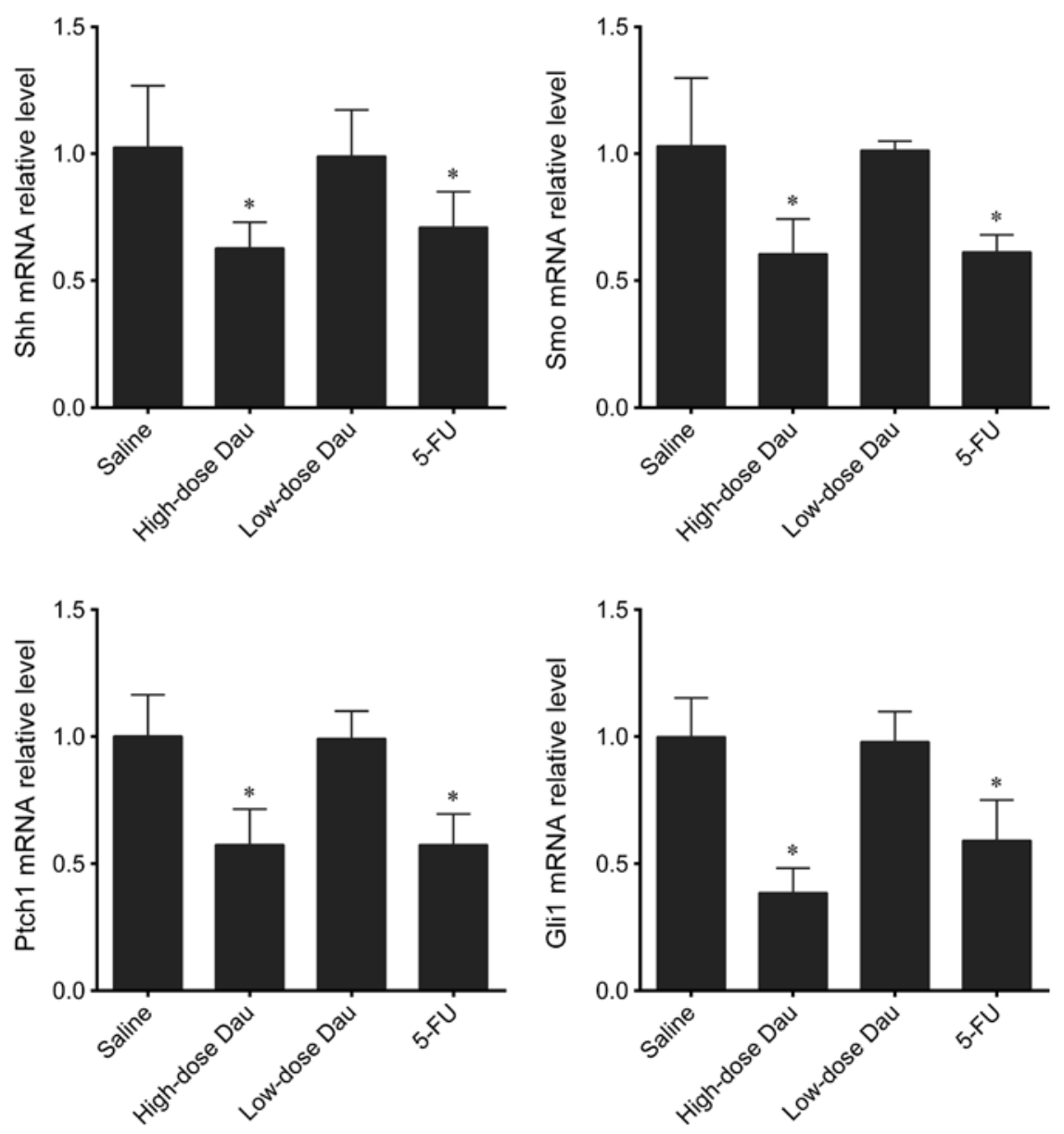

Figure 7. Effects of dauricine on mRNA expression levels of Shh, Smo, Ptch1 and Gli1 in pancreatic cancer BxPC-3 xenografts. GAPDH was used as an internal control. mRNA expression levels are expressed as fold-change relative to the saline group. ${ }^{*} \mathrm{P}<0.05$ vs. saline. Dau, dauricine; 5-FU, 5-fluorouracil; Gli1, glioma-associated oncogene family zinc finger 1; Ptch1, patched 1; Shh, sonic hedgehog signaling molecule; Smo, smoothened, frizzled class receptor.

$\mathrm{G}_{1}$ cell cycle arrest. The TEM results of the present study revealed that treatment with dauricine and 5-FU induced apoptosis. The TEM results were further verified by flow cytometry, which demonstrated an increased number of apoptotic cells following treatment with dauricine or 5-FU. The effects of dauricine on the apoptosis of BxPC-3 cells were also tested in vitro (data not shown) and were similar to the in vivo results. Cell cycle analysis also demonstrated $\mathrm{G}_{1}$ phase arrest following drug treatment. The results of the present study were consistent with a previous study in which dauricine inhibited the viability and proliferation of renal carcinoma cell lines by enhancing apoptosis and inducing cell cycle arrest in the $G_{0} / G_{1}$ phase, and by activating caspase- 9 and caspase-3 (31). Dauricine has also been demonstrated to downregulate the expression levels of anti-apoptotic genes (survivin, BCL2 apoptosis regulator, X-linked inhibitor of apoptosis and inhibitor of apoptosis protein 1) in colon cancer cells (24). The effects of dauricine on pro-and anti-apoptotic gene expression need to be further investigated in pancreatic cancer cells.

The induction of apoptosis and cell cycle arrest by dauricine and 5-FU in pancreatic cancer may be mediated by the inhibition of the Hh signaling pathway. The Hh signaling pathway is activated in several malignant tumors, including pancreatic, prostate, liver, ovarian and breast cancer. Genetic alterations in the Hedgehog signaling pathway were observed in 24 pancreatic cancer patients studied by a global genomic analysis (18). Additionally, our previous study using a phenolic alkaloid mixture demonstrated the involvement of the Hh signaling pathway (30). To the best of our knowledge, no previous data has been published regarding the effects of pure dauricine on pancreatic cancer. However, dauricine has been demonstrated to inhibit cell viability and proliferation and, to induce apoptosis of renal and colon cancer cells via the phosphoinositide 3-kinase/protein kinase B and NF- $\mathrm{BB}$ signaling pathways $(26,31)$.

The Hh signaling pathway was first identified in the common fruit fly (44). The biological effects of the Hh pathway are exerted through signal transmission from the cell membrane to the nucleus, which regulates the balance of activators and repressors of Gli transcription factors $(10,11)$. The components of the Hh signaling pathway include Hedgehog ligands, Ptch1, Ptch2 and Smo. Shh activates Smo by relieving the inhibitory effect of Ptch on Smo (45). Ptch is a membrane receptor and a tumor suppressor (26,46-48). Ptch1 and Ptch2 are homologs of Ptch in humans, which bind with Shh and activate Smo (49). Smo is a proto-oncogene and a key factor in the Hh signaling pathway (50), which activates the downstream transcription factor of the Gli family. The Gli family includes three molecules: Gli1, Gli2 and Gli3 (51). Gli1 is a potent transcriptional 
activator (10); Gli2 also acts as a transcriptional activator, whereas Gli3 mainly acts as a transcriptional repressor (52).

The activation of the Hh signaling pathway is rarely detected in normal human tissue samples; however, it is necessary for the survival and proliferation of pancreatic cancer cells (53). The expression of Hh molecules is increased in pancreatic cancer cell lines and human pancreatic cancer tissue samples $(54,55)$. The proliferation and metastasis of human pancreatic cancer cells have been demonstrated to be closely associated with abnormal expression levels of Shh, Ptch1 and Smo $(56,57)$. In the early stage of pancreatic cancer development, activation of the Hh signaling pathway induces malignant transformation of the pancreatic ductal epithelium. Several Hh signaling pathway inhibitors, including vismodegib and sonidegib, have been developed for cancer treatment $(12,18)$. Inhibition of the Hh signaling pathway may be a potential therapeutic target for pancreatic cancer. The present study identified high mRNA and protein expression levels of Shh, Ptch1, Smo and Gli1 in pancreatic cancer BxPC-3 xenografts in nude mice, which was consistent with the aforementioned observations. High-dose dauricine and 5-FU significantly decreased the mRNA and protein expression levels of these molecules in pancreatic cancer xenografts, which was demonstrated by RT-qPCR, immunohistochemistry and western blotting. The low-dose dauricine treatment group exhibited no differences in mRNA expression, but lower protein expression levels of Shh, Ptch1, Smo and Gli1 compared with the saline group were observed in the western blot, but not in the immunohistochemistry assay. To date, the inhibitory effect of dauricine on the $\mathrm{Hh}$ signaling pathway has not been reported. However, some studies have demonstrated that the inhibitory effects of other natural products on pancreatic cancer are mediated by the inhibition of the $\mathrm{Hh}$ signaling pathway. An active component from Siegesbeckia glabrescens, germacranolide sesquiterpene lactone, inhibited Gli-mediated transcriptional activity in human pancreatic cancer AsPC-1 and PANC-1 cells, and decreased cancer cell proliferation and the expression of Gli-targeted genes (51). Deguelin, a natural compound from the flavonoid family, has been reported to suppress growth, migration and invasion, and to promote apoptosis in two pancreatic cancer cell lines, PANC-1 and BxPC-3, through suppression of the Hh signaling pathway (58). These findings suggested that suppression of the Hh pathway expression may represent a new mechanism for the treatment of pancreatic cancer.

BxPC-3 cells are a wild-type KRAS proto-oncogene, GTPase (KRAS) pancreatic cancer cell line. KRAS is the most common mutated oncogene; studies have indicated that $90 \%$ of patients with pancreatic cancer have KRAS mutations (59). However, one recent study demonstrated that out of 91 patients with pancreatic cancer, 49 had KRAS mutations, whereas 42 had a wild-type KRAS genotype (60). The study also revealed that mutant KRAS tumors exhibit higher expression levels of Shh and Ihh compared with wild-type KRAS tumors, which suggested that KRAS-mutated tumors may benefit from Hh inhibitors. To date, to the best of our knowledge, there are no published studies on the effects of dauricine on mutant KRAS pancreatic cancer cells. Future work is necessary to compare the antitumor function of dauricine in wild-type and mutant KRAS pancreatic cancer cells.
In conclusion, high-and low-dose dauricine treatment suppressed the growth of BxPC-3 pancreatic cancer xenografts in nude mice with no significant changes in the spleen index. Dauricine induced apoptosis and cell cycle arrest in tumor cells from BxPC-3 pancreatic cancer xenografts. The inhibitory effect of dauricine was likely mediated by suppression of the abnormally activated Hh signaling pathway, as gene and protein expression levels of Shh, Ptch1, Smo and Gli1 were decreased following dauricine treatment. The effects of dauricine were similar to those of 5-FU. The results of the present study suggest that dauricine may represent a promising anticancer agent for the treatment of pancreatic cancer.

\section{Acknowledgements}

Not applicable.

\section{Funding}

This study was supported by the Heilongjiang Provincial Department of Education Project (grant nos. 11521323 and 12531788), the Heilongjiang Qiqihar Medical College Doctor Scientific Research Fund (grant nos. QY2016B-26 and QY2016B-21), the Heilongjiang Qiqihar Technology Office Fund (grant no. SFGG-201630), the National Natural Science Foundation of China (grant nos. 81373777 and 81173599), the Heilongjiang Provincial Postdoctoral Program (grant no. LBH-Z14196), the China Postdoctoral Fund Project (grant no. 2015M581496) and the Heilongjiang Province Natural Science Fund Project (grant no. QC2015101).

\section{Availability of data and materials}

The datasets used and/or analyzed during the current study are available from the corresponding author on reasonable request.

\section{Authors' contributions}

YBZ, HXF and JG designed the study. YJZ, HXF, JG, XJZ, SLW and LLZ collected and analyzed the data. YBZ, HXF and JG drafted and wrote the manuscript. HXF critically revised the manuscript. All authors had intellectual input into the study and approved the final version of the manuscript.

\section{Ethics approval and consent to participate}

All animal protocols were approved by the Animal Care and Use Committee at the Heilongjiang University of Chinese Medicine (Harbin, China). All procedures in the animal studies were performed in accordance with the ethical standards of the institution or practice.

\section{Patient consent for publication}

Not applicable.

\section{Competing interests}

The authors declare that they have no competing interests. 


\section{References}

1. Wolfgang CL, Herman JM, Laheru DA, Klein AP, Erdek MA, Fishman EK and Hruban RH: Recent progress in pancreatic cancer. CA Cancer J Clin 63: 318-348, 2013.

2. Veisani Y, Jenabi E, Khazaei S and Nematollahi S: Global incidence and mortality rates in pancreatic cancer and the association with the human development index: Decomposition approach. Public Health 156: 87-91, 2018.

3. Lin QJ, Yang F, Jin C and Fu DL: Current status and progress of pancreatic cancer in China. World J Gastroenterol 21: 7988-8003, 2015.

4. Wu AA, Jaffee $\mathrm{E}$ and Lee V: Current status of immunotherapies for treating pancreatic cancer. Curr Oncol Rep 21: 60, 2019.

5. Moutinho-Ribeiro P, Macedo G and Melo SA: Pancreatic cancer diagnosis and management: Has the time come to prick the bubble? Front Endocrinol (Lausanne) 9: 779, 2019.

6. Rahib L, Fleshman JM, Matrisian LM and Berlin JD: Evaluation of pancreatic cancer clinical trials and benchmarks for clinically meaningful future trials: A systematic review. JAMA Oncol 2: $1209-1216,2016$

7. Ilic M and Ilic I: Epidemiology of pancreatic cancer. World J Gastroenterol 22: 9694-9705, 2016.

8. Jeune F, Coriat R, Prat F, Dousset B, Vaillant JC and Gaujoux S: Pancreatic cancer surgical management. Presse Med 48 e147-e158, 2019.

9. Marigo V, Roberts DJ, Lee SM, Tsukurov O, Levi T, Gastier JM, Epstein DJ, Gilbert DJ, Copeland NG and Seidman CE: Cloning, expression, and chromosomal location of SHH and IHH: Two human homologues of the Drosophila segment polarity gene hedgehog. Genomics 28: 44-51, 1995.

10. Rimkus TK, Carpenter RL, Qasem S, Chan M and Lo HW: Targeting the sonic hedgehog signaling pathway: Review of smoothened and GLI inhibitors. Cancers (Basel) 8: pii: E22, 2016.

11. Qin S, Sun D, Li H, Li X, Pan W, Yan C, Tang R and Liu X: The effect of SHH-Gli signaling pathway on the synovial fibroblast proliferation in rheumatoid arthritis. Inflammation 39: 503-512, 2016.

12. Skoda AM, Simovic D, Karin V, Kardum V, Vranic S and Serman L: The role of the Hedgehog signaling pathway in cancer: A comprehensive review. Bosn J Basic Med Sci 18: 8-20, 2018.

13. Gu J, Saiyin H, Fu D and Li J: Stroma-a double-edged sword in pancreatic cancer: A lesson from targeting stroma in pancreatic cancer with hedgehog signaling inhibitors. Pancreas 47: 382-389, 2018.

14. Tong W, Qiu L, Qi M, Liu J, Hu K, Lin W, Huang Y and Fu J: GANT-61 and GDC-0449 induce apoptosis of prostate cancer stem cells through a GLI-dependent mechanism. J Cell Biochem 119: 3641-3652, 2018

15. Ding J, Zhou XT, Zou HY and Wu J: Hedgehog signaling pathway affects the sensitivity of hepatoma cells to drug therapy through the ABCC1 transporter. Lab Invest 97: 819-832, 2017

16. Song X, Yan L, Lu C, Zhang C, Zhu F, Yang J, Jing H, Zhang Y, Qiao J and Guo H: Activation of hedgehog signaling and its association with cisplatin resistance in ovarian epithelial tumors. Oncol Lett 15: 5569-5576, 2018.

17. Wang X, Wei S, Zhao Y, Shi C, Liu P, Zhang C, Lei Y, Zhang B, Bai B and Huang Y: Anti-proliferation of breast cancer cells with itraconazole: Hedgehog pathway inhibition induces apoptosis and autophagic cell death. Cancer Lett 385: 128-136, 2017.

18. Jones S, Zhang X, Parsons DW, Lin JC, Leary RJ, Angenendt P, Mankoo P, Carter H, Kamiyama H, Jimeno A, et al: Core signaling pathways in human pancreatic cancers revealed by global genomic analyses. Science 321: 1801-1806, 2008.

19. Pasca di Magliano M, Sekine S, Ermilov A, Ferris J, Dlugosz AA and Hebrok M: Hedgehog/Ras interactions regulate early stages of pancreatic cancer. Genes Dev 20: 3161-3173, 2006

20. Gan H, Liu H, Zhang H, Li Y, Xu X, Xu X and Xu J: SHh-Gli1 signaling pathway promotes cell survival by mediating baculoviral IAP repeat-containing 3 (BIRC3) gene in pancreatic cancer cells. Tumour Biol 37: 9943-9950, 2016.

21. Katoh Y and Katoh M: Hedgehog target genes: Mechanisms of carcinogenesis induced by aberrant hedgehog signaling activation. Curr Mol Med 9: 873-886, 2009.
22. Feldmann G, Dhara S, Fendrich V, Bedja D, Beaty R, Mullendore M, Karikari C, Alvarez H, Iacobuzio-Donahue C, Jimeno A, et al: Blockade of hedgehog signaling inhibits pancreatic cancer invasion and metastases: A new paradigm for combination therapy in solid cancers. Cancer Res 67: 2187-2196, 2007.

23. Wang J, Li Y, Zu XB, Chen MF and Qi L: Dauricine can inhibit the activity of proliferation of urinary tract tumor cells. Asian Pac J Trop Med 5: 973-976, 2012.

24. Yang Z, Li C, Wang X, Zhai C, Yi Z, Wang L, Liu B, Du B, Wu H, Guo X, et al: Dauricine induces apoptosis, inhibits proliferation and invasion through inhibiting NF-kappaB signaling pathway in colon cancer cells. J Cell Physiol 225: 266-275, 2010.

25. Chen S, Liu L, Yang Y, Dai Z and Zeng F: Metabolism of dauricine and identification of its main metabolites. J Tongji Med Univ 20: 253-256, 2000.

26. Yang Y, Tian X, Xie X, Zhuang $Y, W u ~ W$ and Wang W: Expression and regulation of hedgehog signaling pathway in pancreatic cancer. Langenbecks Arch Surg 395: 515-525, 2010.

27. Li YH and Gong PL: Neuroprotective effect of dauricine in cortical neuron culture exposed to hypoxia and hypoglycemia: Involvement of correcting perturbed calcium homeostasis. Can J Physiol Pharmacol 85: 621-627, 2007.

28. Liu QN, Zhang L, Gong PL, Yang XY and Zeng FD: Inhibitory effects of dauricine on early afterdepolarizations and L-type calcium current. Can J Physiol Pharmacol 87: 954-962, 2009.

29. Zhao J, Lian Y, Lu C, Jing L, Yuan H and Peng S: Inhibitory effects of a bisbenzylisoquinline alkaloid dauricine on HERG potassium channels. J Ethnopharmacol 141: 685-691, 2012.

30. Zhou ZG, Zhang CY, Fei HX, Zhong LL and Bai Y: Phenolic alkaloids from Menispermum dauricum inhibits BxPC-3 pancreatic cancer cells by blocking of Hedgehog signaling pathway. Pharmacogn Mag 11: 690-697, 2015.

31. Zhang S, Ren Y and Qiu J: Dauricine inhibits viability and induces cell cycle arrest and apoptosis via inhibiting the PI3K/Akt signaling pathway in renal cell carcinoma cells. Mol Med Rep 17: 7403-7408, 2018.

32. Livak KJ and Schmittgen TD: Analysis of relative gene expression data using real-time quantitative PCR and the 2(-Delta Delta C(T)) method. Methods 25: 402-408, 2001.

33. Tang XD, Zhou X and Zhou KY: Dauricine inhibits insulin-like growth factor-I-induced hypoxia inducible factor lalpha protein accumulation and vascular endothelial growth factor expression in human breast cancer cells. Acta Pharmacol Sin 30: 605-616, 2009.

34. Deveci HA, Nazıroğlu M and Nur G: 5-Fluorouracil-induced mitochondrial oxidative cytotoxicity and apoptosis are increased in MCF-7 human breast cancer cells by TRPV1 channel activation but not Hypericum perforatum treatment. Mol Cell Biochem 439: 189-198, 2018.

35. Cunningham TJ, Tabacchi M, Eliane JP, Tuchayi SM, Manivasagam S, Mirzaalian H, Turkoz A, Kopan R, Schaffer A, Saavedra AP, et al: Randomized trial of calcipotriol combined with 5-fluorouracil for skin cancer precursor immunotherapy. J Clin Invest 127: 106-116, 2017.

36. Mahlberg R, Lorenzen S, Thuss-Patience P, Heinemann V, Pfeiffer P and Möhler M: New perspectives in the treatment of advanced gastric cancer: S-1 as a novel oral 5-fu therapy in combination with cisplatin. Chemotherapy 62: 62-70, 2017.

37. Liu J, Wang Z, Wu K, Li J, Chen W, Shen Y and Guo S: Paclitaxel or 5-fluorouracil/esophageal stent combinations as a novel approach for the treatment of esophageal cancer. Biomaterials 53: 592-599, 2015.

38. Bash-Imam Z, Thérizols G, Vincent A, Lafôrets F, Polay Espinoza M, Pion N, Macari F, Pannequin J, David A, Saurin JC, et al: Translational reprogramming of colorectal cancer cells induced by 5 -fluorouracil through a miRNA-dependent mechanism. Oncotarget 8: 46219-46233, 2017.

39. Shim IK, Yi HJ, Yi HG, Lee CM, Lee YN, Choi YJ, Jeong SY, Jun E, Hoffman RM, Cho DW and Kim SC: Locally-applied 5-fluorouracil-loaded slow-release patch prevents pancreatic cancer growth in an orthotopic mouse model. Oncotarget 8: 40140-40151, 2017.

40. Longley DB, Harkin DP and Johnston PG: 5-fluorouracil: Mechanisms of action and clinical strategies. Nat Rev Cancer 3: 330-338, 2003

41. Wang Y, Han Q and Zhang H: Evaluation of the toxicity of 5-fluorouracil on three digestive enzymes from the view of side effects. Spectrochim Acta A Mol Biomol Spectrosc 220: 117105, 2019. 
42. Esin E, Telli TA, Yuce D and Yalcin S: A correlation study of fluorouracil pharmacodynamics with clinical efficacy and toxicity. Tumori 104: 157-164, 2018.

43. Jin H, Dai J, Chen X, Liu J, Zhong D, Gu Y and Zheng J: Pulmonary toxicity and metabolic activation of dauricine in CD-1 mice. J Pharmacol Exp Ther 332: 738-746, 2010.

44. Mohler J: Requirements for hedgehog, a segmental polarity gene, in patterning larval and adult cuticle of Drosophila. Genetics 120 $1061-1072,1988$

45. Du Z, Zhou F, Jia Z, Zheng B, Han S, Cheng J, Zhu G and Huang P: The hedgehog/Gli-1 signaling pathways is involved in the inhibitory effect of resveratrol on human colorectal cancer HCT116 cells. Iran J Basic Med Sci 19: 1171-1176, 2016.

46. Mizukoshi K, Koyama N, Hayashi T, Zheng L, Matsuura S and Kashimata M: Shh/Ptch and EGF/ErbB cooperatively regulate branching morphogenesis of fetal mouse submandibular glands. Dev Biol 412: 278-287, 2016.

47. Wang LW, Lin H, Lu Y, Xia W, Gao J and Li ZS: Sonic hedgehog expression in a rat model of chronic pancreatitis. World J Gastroenterol 20: 4712-4717, 2014

48. Kayed H, Kleeff J, Keleg S, Guo J, Ketterer K, Berberat PO, Giese N, Esposito I, Giese T, Buchler MW and Friess H: Indian hedgehog signaling pathway: Expression and regulation in pancreatic cancer. Int J Cancer 110: 668-676, 2004.

49. Gao J, Li Z, Chen Z, Shao J, Zhang L, Xu G, Tu Z and Gong Y: Antisense Smo under the control of the PTCH1 promoter delivered by an adenoviral vector inhibits the growth of human pancreatic cancer. Gene Ther 13: 1587-1594, 2006.

50. Han JB, Hua YQ, Chen LY and Liu LM: Advances in Smoothened-targeting therapies for pancreatic cancer: Implication for drug discovery from herbal medicines. Zhong $\mathrm{Xi}$ Yi Jie He Xue Bao 10: 256-263, 2012.
51. Lee HJ, Wu Q, Li H, Bae GU, Kim AK and Ryu JH: A sesquiterpene lactone from Siegesbeckia glabrescens suppresses Hedgehog/Gli-mediated transcription in pancreatic cancer cells. Oncol Lett 12: 2912-2917, 2016.

52. Bai CB, Stephen D and Joyner AL: All mouse ventral spinal cord patterning by hedgehog is Gli dependent and involves an activator function of Gli3. Dev Cell 6: 103-115, 2004.

53. Gupta S, Takebe N and Lorusso P: Targeting the Hedgehog pathway in cancer. Ther Adv Med Oncol 2: 237-250, 2010.

54. Hao K, Tian XD, Qin CF, Xie XH and Yang YM: Hedgehog signaling pathway regulates human pancreatic cancer cell proliferation and metastasis. Oncol Rep 29: 1124-1132, 2013.

55. Hidalgo $\mathrm{M}$ and Maitra A: The hedgehog pathway and pancreatic cancer. N Engl J Med 361: 2094-2096, 2009.

56. Kelleher FC: Hedgehog signaling and therapeutics in pancreatic cancer. Carcinogenesis 32: 445-451, 2011.

57. Dosch JS, Pasca di Magliano M and Simeone DM: Pancreatic cancer and hedgehog pathway signaling: New insights. Pancreatology 10: 151-157, 2010.

58. Zheng W, Lu S, Cai H, Kang M, Qin W, Li C and Wu Y: Deguelin inhibits proliferation and migration of human pancreatic cancer cells in vitro targeting hedgehog pathway. Oncol Lett 12: 2761-2765, 2016

59. Lennerz JK and Stenzinger A: Allelic ratio of KRAS mutations in pancreatic cancer. Oncologist 20: e8-e9, 2015.

60. Agarwal A and Saif MW: KRAS in pancreatic cancer. Jop 15: 303-305, 2014.

This work is licensed under a Creative Commons Attribution-NonCommercial-NoDerivatives 4.0 International (CC BY-NC-ND 4.0) License. 